\section{ENSINO DE LÍNGUAS ESTRANGEIRAS NO CURRÍCULO DA EDUCAÇÃO BÁSICA: PERCURSO E PERCALÇOS ${ }^{1}$}

\section{TEACHING FOREIGN LANGUAGES IN THE BASIC EDUCATION CURRICULUM: COURSE AND MISHAPS}

\section{Lucimar Araujo Braga*}

UEPG

\section{Ligia Paula Couto** \\ $U E P G$}

Resumo: Este artigo é resultado de pesquisa na área de formação de professores, em desenvolvimento em projetos de pesquisa e extensão de nossa autoria, na Universidade Estadual de Ponta Grossa. A metodologia utilizada é a pesquisa qualitativa e o objetivo é realizar uma investigação sobre a situação das línguas estrangeiras nos currículos educacionais brasileiros, desde a educação jesuíta, até a aprovação da LEI 11.161/2005 e de sua revogação, em 2017, com a LEI 13.415/2017, que abrangem, respectivamente, a inserção/exclusão da língua espanhola nos currículos do ensino médio no Brasil. Por se tratar de uma investigação documental, os dados foram coletados em literatura da área e documentos oficiais relacionados à educação formal. Os resultados apontam para a manutenção de certo monolinguismo da língua inglesa e de descaso para com as demais línguas estrangeiras nos currículos brasileiros.

Palavras-chave: Línguas estrangeiras. Currículo. Educação básica.

\begin{abstract}
This article is the result of a research in teaching education, which is being developed in research and extension projects at Universidade Estadual de Ponta Grossa. The methodology is qualitative and the objective is to investigate the foreign languages in the Brazilian curriculum, from Jesuit Education to the approval of LAW 11.161/2005 and its revocation in 2017, by the LAW 13.415/2017, which comprehend, respectively, the insertion/exclusion of Spanish language in high school in Brasil. As it is a documental investigation, the data was collected in the literature of the área and official documents related to formal education. The results point the maintenance of certain monolinguism of English language and lack of importance to other foreign languages in the Brazilian curriculum.
\end{abstract}

Keywords: Foreign languages. Curriculum. Elementary and high school.
${ }^{1}$ Parte deste texto está na dissertação "Crenças e atitudes de uma professora de espanhol de uma escola pública do interior do Paraná e as políticas linguísticas”, apresentada em 29-08-2013 ao Programa de Pós-Graduação em Educação da Universidade Estadual de Ponta Grossa. Disponível em: http://tede2.uepg. br/jspui/bitstream/ prefix/452/1/Braga\%2C\%20\%20Lucimar\%20Araujo.pdf.

* Doutoranda em Educação. E-mail: labraga2007@gmail. com

${ }^{* *}$ Doutora em Educação. E-mail: ligiapaula@yahoo. com 


\section{Introdução}

Este artigo é fruto de pesquisa, ensino e extensão em desenvolvimento na Universidade Estadual de Ponta Grossa - UEPG, a partir de nossa atuação profissional como professoras, pesquisadoras e extensionistas.

Entendemos que as transformações globais percebidas e vivenciadas por nós, em todas as áreas de conhecimento, proporcionam novas organizações dos indivíduos e instituições e a educação faz parte deste globo. Nesse sentido, entender quais foram os movimentos percorridos pelas línguas estrangeiras no currículo educacional brasileiro é fundamental para seguirmos com as nossas pesquisas na área e trazermos conosco futuros professores, pesquisadores e extensionistas.

Neste artigo, apresentamos uma breve síntese deste percurso e alguns percalços vivenciados por professores de línguas estrangeiras. Mais especificamente, focamos a língua espanhola, traçando um paralelo entre esta língua e as outras línguas estrangeiras que, de alguma forma, fizeram parte do currículo brasileiro.

Além disso, discorremos sobre as leis de inserção e exclusão das línguas estrangeiras no currículo e as possíveis consequências desses movimentos políticos na sociedade e de política linguística na educação, que refletiram tanto nas escolas como na coletividade como um todo, pois, ademais de implicar diretamente em crenças e costumes de grupos étnicos de comunidades linguísticas estrangeiras e indígenas locais, cada alteração implicava em mudança no currículo educacional.

Assim, por meio de uma análise das leis e documentos, trazemos algumas considerações sobre esse percurso, bem como sobre os percalços que se fizeram presentes no trajeto progressivo dos fatos que abrangeram o tratamento dado às línguas estrangeiras no currículo educacional brasileiro. Para isso, selecionamos os trechos extraídos dos documentos e os analisamos em comparação com a literatura escolhida para amparar esta pesquisa. Por isso, este artigo está organizado em uma única seção em que a teoria se mescla à análise e ambas são desenvolvidas ao longo do texto e o finalizamos com as nossas considerações finais.

\section{O percurso histórico, as leis e as normas que regem a inserção/ exclusão de conteúdo no currículo}

Iniciamos este texto trazendo um pouco da história do ensino e da aprendizagem das línguas estrangeiras na educação formal do Brasil, primeiramente de forma mais geral, para, em seguida, restringirmos a questão ao estado do Paraná. Para isso, partimos de um retrospecto que se inicia no século XIX. Essa opção relaciona-se à literatura encontrada sobre o assunto que pode nos auxiliar a compreender o tratamento dado às línguas estrangeiras 
na escola, ora inseridas na parte diversificada, ora na parte obrigatória, das grades curriculares da Educação Básica brasileira.

Para que possamos compreender melhor os movimentos econômicos, políticos e sociais que influenciam a educação, seja por força de lei ou de projetos políticos pedagógicos, é importante entender como eles adentram a escola. Para Tadeu da Silva (2004), é por meio da ideologia veiculada pelo currículo. Segundo o autor:

A escola atua ideologicamente através de seu currículo, seja de uma forma mais direta, através das matérias mais suscetíveis ao transporte de crenças explícitas sobre a desejabilidade das estruturas sociais existentes, como estudos Sociais, História, Geografia, por exemplo; seja de uma forma mais indireta, através de disciplinas mais "técnicas”, como Ciências e Matemática. Além disso, a ideologia atua de forma discriminatória: ela inclina as pessoas das classes subordinadas à submissão e à obediência, enquanto as pessoas das classes dominantes aprendem a comandar e a controlar (TADEU DA SILVA, 2004, p. 31-32, grifos nossos).

Ou seja, nas palavras de Tadeu da Silva (2004), as disciplinas que circulam nas grades curriculares das escolas parecem estar atreladas ideologicamente a uma estrutura de reprodução. Para melhor exemplificar o sentido atribuído à noção de “reprodução”, podemos dizer que as ideologias presentes nos currículos escolares procuram seguir uma receita em que o conhecimento é moldado para finalidades outras que não a reflexão.

Segundo Picanço (2003), esse movimento ideológico teve início quando do término do período de educação jesuíta, época em que a educação formal foi retomada pelo Estado brasileiro. A educação pública se encontrava em um estado muito precário porque os jesuítas foram expulsos e a escola para os nativos (índios) e colonizadores que aqui viviam praticamente se acabou. Assim:

A Companhia de Jesus foi fundada em pleno desenrolar do movimento de reação da Igreja Católica contra a Reforma Protestante, podendo ser considerada um dos principais instrumentos da Contra-Reforma nessa luta. Tinha como objetivo sustar o grande avanço protestante da época e, para isso, utilizou-se de duas estratégias: a educação dos homens e dos indígenas; e a ação missionária, por meio das quais procuraram converter à fé católica os povos das regiões que estavam sendo colonizadas. (MACIEL; NETO, 2006, p. 468)

A proposta de educação dos jesuítas trazia, diluídos ideologicamente, objetivos muito mais religiosos que educacionais; entretanto, de acordo com a história, essa era a única opção educacional da época. Nesse sentido, diante das dificuldades políticas que o Estado brasileiro começava a vivenciar, começava a despontar a educação privada que se firmava em meio à burguesia, 
passando, inclusive, em nosso entendimento, a exercer um importante papel de reprodutora e ratificadora das crenças e costumes da época.

Essa era, talvez, uma das maneiras mais eficazes de os nobres se sobreporem às classes desprivilegiadas, que não tinham como chegar à escola. "Nestes casos, [o ensino de] língua estrangeira servia como exercício de erudição e destinava-se, assim como as demais disciplinas, a formar a elite do país [...]" (PICANÇO, 2003, p. 28). Mesmo porque, "na administração de Pombal, há uma tentativa de atribuir à Companhia de Jesus todos os males da Educação na metrópole e na colônia, motivo pelo qual os jesuítas são responsabilizados pela decadência cultural e educacional imperante na sociedade portuguesa” (MACIEL, NETO, 2006, p. 469).

Nesse sentido, de acordo com Picanço (2003), o contexto histórico que envolvia a condução das políticas voltadas para a educação nacional tinha a pretensão de controlar o ensino ofertado, por meio da definição da estrutura dos programas curriculares como base nos programas adotados pelo Colégio Pedro II². Vejamos:

Para exercer o seu papel de controle, era preciso que se uniformizassem conteúdos e modelos de avaliação. Portanto, as aulas por disciplinas foram substituídas por classes de alunos e programas de ensino comuns. Neste momento se consolida a ideia de currículo como conjunto de programas, e os do Colégio Pedro II se tornaram oficiais. Nesses programas curriculares oficiais, que copiavam a França no modelo de educação, em sua ênfase no ensino clássico e humanista, constam aulas de francês, inglês e alemão, distribuídas nos últimos anos da escola secundária. O italiano e o espanhol não faziam parte do currículo do Pedro II. (PICANÇO, 2003, p. 28)

Como é possível perceber, a uniformização dos conteúdos passa a ser feita por meio da criação dos currículos. Para a efetivação dessa padronização, o Estado brasileiro busca na França um modelo que delineasse algumas características clássicas e humanísticas a serem aplicadas na educação. Assim, é a primeira vez que afirma explicitamente quais línguas estrangeiras deveriam estar inseridas na educação secundária da época.

O que apreendemos por meio desta proposta organizada em forma de currículo é uma estruturação dos objetivos que deveriam ser seguidos por escolas, professores e administradores educacionais. Os conteúdos que seriam estudados na educação básica começariam a ser organizados no formato de um currículo com a distribuição das aulas em uma grade curricular.

Somente mais tarde surgiu "a noção de educação nacional', que se consolidou no século XIX, com a criação do Colégio D. Pedro II, a primeira escola pública de nível médio, que passou a ser modelo para as demais escolas secundárias” (PICANÇO, 2003, p. 28).

As proposições emolduradas no formato de currículo de programas implantados no Colégio D. Pedro II especificavam que as línguas inglesa,
${ }^{2}$ Colégio Estadual Dom Pedro II. A

"Escola Presidente Kennedy” era uma escola destinada à formação das "professorinhas” por meio do curso "Normal”, de nível médio, inicialmente localizado no Bingen, um bairro de Petrópolis, junto ao SENAI. O edifício do Grupo Escolar D. Pedro II foi construído conforme projeto do Arquiteto Heitor de Mello, em terras do ex-Palácio Imperial de Petrópolis, com 50 $\mathrm{m}$ de frente e $160 \mathrm{~m}$ de fundos. Informação disponível em: http://www. cedompedroii.com.br/ historia.html, acesso 16-12-2012.

${ }^{3}$ Ainda que o termo seja nacional, o referencial de Picanço (2003) diz respeito à educação no Paraná. 
francesa e alemã deveriam aparecer na grade curricular. Na década de 30, houve a primeira reforma na educação "[...] que ficou conhecida como a Reforma Francisco Campos” (PICANÇO, 2003, p. 29). Por meio dessa reforma, sugeriram-se propostas que visavam à centralidade não somente na formação humana, como no preparo para o ingresso na universidade.

Na sequência, acontece o golpe de Estado e o estabelecimento do Estado Novo em meio a mudanças políticas. Nesse contexto, as disciplinas de línguas estrangeiras foram sendo substituídas por disciplinas de caráter mais cívico, como história, com foco nos heróis e instituições nacionais, além da "[...] ênfase no catolicismo e uso adequado da língua portuguesa [...]” (PICANÇO, 2003, p. 30, grifos nossos).

Para fortalecer o sentimento nacional, promoveu-se uma tentativa de conter o desenvolvimento das minorias étnicas, linguísticas e culturais que se haviam constituído no Brasil do início do século, e colocá-las sob o jugo do governo. Para isso foram envolvidos quase todos os ministérios, desde o da Guerra até o do Trabalho, passando pela Educação e da Justiça. Várias medidas passaram a cercear a liberdade dos colonos, principalmente dos alemães. Em ofício enviado ao Ministro da Guerra, o então Chefe do Estado-Maior do Exército, General Pedro Aurélio de Góis Monteiro, tenta mostrar os perigos que a presença de núcleos estrangeiros organizados traziam à segurança nacional. (PICANÇO, 2003, p. 30).

Como se pode observar, no Brasil do Estado Novo, a construção de uma "identidade nacional” sustentava-se em grande parte na homogeneidade linguística “obtida” ou "garantida” por meio da exigência de uma apropriação adequada da língua portuguesa por todos os brasileiros. Por essa razão, os direitos de falar e aprender (em) outras línguas, diferentes da língua portuguesa, foram tolhidos e as minorias étnicas, linguísticas e culturais passaram a ser perseguidas, já que, segundo o governo, representavam riscos para a segurança nacional. Como consequência, passou-se a alimentar a aversão ao estrangeiro e muitas escolas de comunidades de imigrantes que utilizavam suas línguas na alfabetização de seus alunos fecharam as portas (ou melhor, tiveram suas portas fechadas) ou perderam a autonomia.

Evidentemente, que o posicionamento do governo brasileiro tinha motivações políticas, econômicas e sociais. Em decorrência dos fatos, as perseguições podem ser apresentadas como exemplo de desrespeito ao outro, ou seja, são atitudes que contrariam o que hoje conhecemos como direitos linguísticos universais, já que desconsideravam a questão da diversidade na elaboração das políticas linguísticas, uma vez que o sujeito tem direito a estudar e aprender outras línguas.

Isso implica, como direitos fundamentais, o direito de cada indivíduo a aprender e desenvolver livremente sua própria língua materna, a receber educação pública através dela, a usá-la em contextos oficiais socialmente 
relevantes, e a aprender pelo menos uma das línguas oficiais do seu país de residência. (HAMEL, 2003, p. 51).

Nesse sentido, o impedimento da liberdade de falar e de utilizar sua língua materna impõe ideológica e economicamente línguas de grupos que detêm mais status com suas culturas, crenças e costumes, como foi o caso da língua imposta pelos colonizadores aos brasileiros.

No entanto, podemos considerar que, de uma forma ou de outra, todas as comunidades podem se organizar e defender seus espaços, tanto as que detêm poder em escalas grandiosas, como as mais limitadas. O que aconteceu em quase toda a América Latina foram imposições de governos ditatoriais impossibilitando maiores avanços em relação à compreensão dos direitos universais do cidadão, como o direito de ir e vir, de falar (em) sua língua, de manifestar sua cultura. Por outro lado, se a violência dos dirigentes ditadores retarda os movimentos de compreensão dos direitos universais de cada um, não impede que as comunidades se organizem e se manifestem, conforme nos apresenta Hamel (2003).

Especificamente no Brasil, a ditadura se apoiava em uma ideia de “identidade nacional” em construção que encontrava eco no regime político do Estado Novo. Para lograr êxito, prometia-se “[...] um ideal de pátria representado por um único idioma, um único povo, uma única ideologia [...]”. Esse momento foi uma ótima oportunidade para que, no Brasil da época, se instalasse um “[...] sentimento de aversão ao estrangeiro [...]” (PICANÇO, 2003, p. 31), cujo reflexo maior, em termos de ensino de línguas estrangeiras, foi a diminuição da possibilidade de intensificar os movimentos em prol de uma maior visibilidade às línguas estrangeiras, nas grades curriculares, diminuição essa justificada pelo argumento, utilizado pelo governo, de que se deve aprender somente o idioma que, de fato, representa o povo brasileiro, a língua portuguesa.

Na sequência, em 1942, a reforma de Capanema estabelece a divisão entre o ginásio, que passa a ter quatro anos e o secundário, ciclo de três anos, com a opção entre o clássico e o científico. A reforma do ensino secundário mantém a ênfase no ensino humanístico de tipo clássico. Os conteúdos de caráter nacionalista são ainda mais valorizados e teoricamente o aluno é preparado dentro de uma proposta de conhecimentos gerais.

A partir dessa reforma, as línguas francesa, inglesa e espanhola, que eram oferecidas no ensino fundamental, vêm substituir o alemão. O latim e o grego eram estudados durante os três anos do ensino clássico, além de filosofia e história natural, ou seja, as línguas estrangeiras não eram automaticamente excluídas das grades curriculares. O ensino secundário era formado pelas modalidades colegial clássico e colegial científico e as disciplinas de tronco comum eram: “[...] português, francês, inglês, matemática, 
física, química, história geral e do Brasil, e geografia geral e do Brasil” (PICANÇO, 2003, p. 33).

Entretanto, o trabalho com as línguas estrangeiras passou a acontecer sob a ressalva de que o ensino e a aprendizagem de línguas contribuíssem para a formação educacional do aprendiz de modo que esse conhecesse, observasse e refletisse sobre os hábitos e a cultura do estrangeiro. A maneira como essa advertência era passada pelos documentos a que tivemos acesso parece insinuar que o aprendiz deveria ser cauteloso ao conhecer a língua e os costumes do estrangeiro. Ou seja, a princípio, a proposta de refletir sobre os hábitos e a cultura do outro não tinha unicamente a finalidade de ampliar nossos conhecimentos culturais, mas também o objetivo de permitir que conhecêssemos o outro (LEI 5692-71).

É nesse contexto que a língua espanhola entra no currículo do ensino secundário, para contemplar autores consagrados como Miguel de Cervantes, Becker e Lope de Vega. De acordo com a concepção da proposta de inserção da língua espanhola nos currículos da década de 1940, esses autores eram representantes de um povo importante para a colonização ocidental. No entanto, aparentemente esse argumento camufla alguma outra intenção: com a extinção da cadeira destinada à língua alemã, a língua espanhola entra “[...] como componente curricular obrigatório ao lado do francês e do inglês [...]” (PICANÇO, 2003, p. 33).

A substituição da língua alemã pela língua espanhola ocorre "em 1942 [quando] o governo Getúlio Vargas determina a substituição do alemão pelo espanhol, motivado [...] pelo fato de o alemão ser a língua do inimigo na $2^{\text {a }}$ Guerra Mundial [...]” (LISBOA, 2009, p. 206). Da mesma forma, as mudanças trazidas pela reforma de 1942 determinam que a língua espanhola fosse incorporada gradualmente "[...] a quase todos os cursos da escola secundária” (PICANÇO, 2003, p. 34).

Por outro lado, mesmo com a entrada da língua espanhola no ensino secundário, o espaço da língua inglesa continua garantido pelo fato de que essa era a língua usada na maioria das transações comerciais. Além disso, politicamente, no momento pós-segunda guerra mundial, o Brasil fica em uma situação de maior dependência em relação aos Estados Unidos nos acordos comerciais, de modo que a necessidade de aprender o inglês também aumenta (LISBOA, 2009).

Com o desenvolvimento econômico, iniciado nos anos 50, em razão do surgimento das indústrias (CAPUTO; MELO, 2009), o currículo, que antes era mais voltado para a área das humanidades, passa a ter um caráter mais técnico, o que levou a uma notória diminuição na carga horária destinada às disciplinas de línguas estrangeiras, tradicionalmente associadas àquela área de conhecimento.

Já na década de 60, pelo surgimento da Lei de Diretrizes e Bases da Educação n 4.024 de 1961 (LDB/61), os estados ficam responsáveis 
pela inclusão ou não da língua estrangeira no então segundo grau e, pela demanda do mercado, a língua inglesa continua sendo a mais valorizada (LISBOA, 2009).

Em 1971, os governantes militares reformaram a LDB/61 e esta foi substituída pela LEI n 5.692/71, que centrava o ensino no desenvolvimento de uma habilidade profissional, o que, pelo entendimento da época, desobrigava o ensino de línguas estrangeiras. Essas seriam trabalhadas apenas de modo instrumental como uma ferramenta específica para certos fins, como a leitura (PICANÇO, 2003).

Desse modo, as disciplinas de línguas estrangeiras mudam de lugar na grade curricular comum, passando à parte de diversificação. Com esse formato, tem início “a democratização do acesso à escola”, com foco em um ensino voltado mais para capacitar pessoas que desempenhassem funções técnicas, que não precisariam necessariamente saber línguas estrangeiras. Para Picanço (2003), “a ampliação da obrigatoriedade de ensino escolar seria o resultado tanto das exigências dos políticos em favor da democratização do ensino, quanto dos industriais e economistas” (PICANÇO, 2003, p. 41), uma vez que, naquele momento, o país necessita de mão de obra capacitada para atuar nas indústrias que se encontram em pleno desenvolvimento.

Assim, em termos de ensino de língua, a LEI 5.692/71 permanece valorizando quase unicamente o português, em razão do seu caráter de língua nacional: "No ensino de $1^{\circ}$. e $2^{\circ}$. graus dar-se-á especial relevo ao estudo da língua nacional, como instrumento de comunicação e como expressão da cultura brasileira” (LDB/71).

Como afirmamos anteriormente, quanto às línguas estrangeiras, estas foram desaparecendo das grades curriculares formais, apesar de a LDB/71 possibilitar, por meio de seu artigo $8^{\circ}$, que “em qualquer grau, poderão organizar-se classes que reúnam alunos de diferentes séries e de equivalentes níveis de adiantamento, para o ensino de línguas estrangeiras e outras disciplinas, áreas de estudo e atividades em que tal solução se aconselhe”. Com base nessa brecha, "muitas escolas mantiveram o ensino de mais de uma língua, na maioria dos casos o inglês e o francês” (PICANÇO, 2003, p. 45). A esse momento histórico, a autora denomina de desprovincialização do país:

O aspecto de desprovincialização na elaboração da lei significava estar sincronizado com as tendências mundiais sem estar atrelado a nenhum modelo cultural como único, fosse europeu ou não. No entanto, durante a sua implantação, a partir de meados da década de 70, passa a significar a adoção do modelo norte-americano (PICANÇO, 2003, p. 45).

Assim, uma das características da desprovincialização está relacionada à tentativa de tornar o Brasil mais internacionalizado, mas, como é possível perceber, a partir dos anos 70, o intento de internacionalizar o país 
acabou enveredando quase exclusivamente para o lado dos Estados Unidos, conforme observamos, a seguir:

Em relação ao inglês, Phillipson (1992), em sua análise do chamado Imperialismo Linguístico da Língua Inglesa, afirma, a partir de documentos oficiais dos governos norte-americano e inglês, que a difusão da língua inglesa ao longo do século XX (patrocinada por esses dois países via Conselho Britânico, por exemplo) atendeu a interesses políticos e econômicos dessas nações (RIBEIRO DA SILVA, 2011, p. 317, grifos do autor).

De acordo com o autor, a língua inglesa compõe o currículo escolar brasileiro desde o império; talvez por este motivo o modelo norte-americano tenha prevalecido, ou seja, torna-se visível qual é a política linguística e cultural praticada pelo Estado brasileiro em termos de ensino de língua estrangeira na escola. O patrocínio de estudos e projetos educacionais mantidos pelo Conselho Britânico impulsiona a manutenção e predomínio de uma única língua estrangeira na grade curricular.

Por essa razão, segundo o autor, se a língua espanhola vivenciasse um momento de incentivo para sua entrada no currículo escolar brasileiro pela obrigatoriedade, por meio da LEI 11.161/2005, mais uma vez se repetiria “[...] uma prática (de política linguística e cultural) largamente utilizada ao longo da história” (RIBEIRO DA SILVA, 2011, p. 317). O que em nosso entendimento não favorece a possibilidade de ensino e aprendizagem imersos em uma diversidade linguística evidenciada no Brasil (OLIVEIRA, 2003).

Nesse contexto e mais especificamente no estado do Paraná dos anos 70 e 80, essa situação passa a ser vivenciada principalmente por escolas que ofertavam mais de uma língua estrangeira, como era o caso do Colégio Estadual do Paraná, que sofreu o impacto da diminuição, no seu quadro de professores, no número de docentes que ministravam outras línguas estrangeiras, além do inglês, porque o governo não dispunha de uma política de investimento na formação de professores (PICANÇO, 2003). E nesse sentido,

[o] francês e o espanhol foram sendo paulatinamente substituídos. Exemplo disso era, em 1971, o quadro de efetivos da área de línguas do Colégio Estadual do Paraná: dos trinta e três professores, dezessete eram de inglês, quase o dobro do número de professores de francês que eram apenas dez. Nessa época ainda existiam quatro professores de latim, um de grego e apenas o professor FRIGÉRIO de espanhol (PICANÇO, 2003, p. 47 - destaque da autora).

As substituições do francês, do espanhol, do latim e do grego pelo inglês podem ter incentivado o aparecimento dos centros de línguas estrangeiras modernas nos estados de São Paulo e Paraná (LISBOA, 2009). Ou seja, com a falta de investimento na contratação de professores para as cadeiras das outras línguas, os professores começaram a se organizar em 
associações para que tivessem como continuar trabalhando em suas áreas de atuação. E os professores que restaram nas escolas, para garantir sua permanência, assumiram aulas de língua portuguesa e se uniram em centros de línguas (PICANÇO, 2003).

De acordo com o que explica Picanço (2003), no final da década de 70 e início de 80, com o início da redemocratização é que voltam as disciplinas de línguas estrangeiras para o núcleo comum. Assim, começam a ser concebidas novas possibilidades de fortalecimento das línguas estrangeiras na escola que, nessa época, como já apontamos - praticamente se restringia à língua inglesa. Há quem afirme que essa política em prol do "só inglês” se explica em razão dos altos investimentos feitos pelos bancos norte-americanos no Brasil, assim como em razão dos acordos firmados entre governo brasileiro com bancos e do panorama mundial que valorizava apenas o inglês, devido às exigências tecnológicas do mercado mundial (PICANÇO, 2003).

Já a língua espanhola, ao contrário, não tinha representatividade política que a elevasse ao patamar de língua estrangeira necessária para o comércio e diplomacia nessa época. A língua espanhola foi mantida apenas nos currículos de escolas de cidades que faziam fronteira com os países hispanófanos, juntamente com a língua inglesa. É dessa forma que, no fim da década de 70, a língua espanhola quase desapareceu das grades curriculares. Em Curitiba, por exemplo, o Colégio Estadual do Paraná manteve a disciplina apenas pela insistência de alguns professores, como o professor Frigério $^{4}$ (PICANÇO, 2003).

Nessa perspectiva, na década de 80, iniciaram-se manifestações pela volta da democracia e, por sua vez, as associações de professores de línguas estrangeiras, insatisfeitas com a realidade vivida, “[...] começam a buscar soluções, individual ou coletivamente” (PICANÇO, 2003, p. 53). No Colégio Estadual do Paraná, por exemplo, foram criados cursos de línguas estrangeiras para atender a demanda de pessoas interessadas em aprendê-las (além de alunos eram atendidas pessoas da comunidade em geral). Além do espanhol, eram ofertadas aulas de inglês, alemão e francês. Nesse momento, nasciam os Centros de Línguas Estrangeiras Modernas (CELEM), que, paulatinamente, foram levados para outras escolas de Curitiba e de outras cidades no Paraná, como Rolândia e Ponta Grossa (primeiras cidades a sediarem os CELEM fora da capital).

Naquela época, para atuar no CELEM, os professores precisavam fazer parte do quadro de docentes efetivos do colégio, exigência que dificultou a manutenção e ampliação dos cursos. Assim, "novamente as iniciativas dos professores esbarravam em limitações impostas pela falta de uma política que garantisse a formação e manutenção de quadros de professores” (PICANÇO, 2003, p. 55).

A autora enfatiza que uma das razões alegadas pelas pessoas que não se interessavam em estudar espanhol dizia respeito ao fato de que, até

\footnotetext{
${ }^{4}$ O professor Francisco Frigério é citado no livro de Picanço (2003).
} 
aquele momento, não era possível, no vestibular, realizar uma prova de espanhol como língua estrangeira. Foi então que nessa mesma década “[...] a professora DEUCÉLIA ${ }^{5}$ fez a proposta de se incluir o idioma como opção para as provas de vestibular” (PICANÇO, 2003, p. 55, caixa alta pela autora). Desse modo, uma ação de política educacional possibilitou, de alguma maneira, a inserção da língua espanhola na educação formal, pois, se fosse conteúdo que pudesse ser exigido no vestibular, teria maior aceitação pela comunidade e alunos das escolas regulares.

De acordo com a entrevista que a professora Deucélia concedeu a Picanço (2003), em 2000, a partir do momento em que se incluiu a prova de língua espanhola como opção no processo de seleção do vestibular da Universidade Federal do Paraná, apareceram, cada vez mais, interessados em estudar espanhol. Pessoas estas que, posteriormente, seriam os professores que ministrariam as aulas preparatórias para os alunos que fariam vestibular na capital paranaense.

\section{A necessidade de uma política plurilíngue}

Diante dos argumentos citados anteriormente, acreditamos que o percurso percorrido pelos professores de línguas estrangeiras, em geral, e especificamente pelos professores de espanhol, no intuito de ampliar a diversidade de oferta de línguas estrangeiras nas grades curriculares do estado do Paraná, foi cheio de percalços, já que, por vários motivos e em muitos momentos, evidenciava-se uma política de descaso para com o ensino de línguas estrangeiras na escola, seja porque estas eram simplesmente retiradas do currículo, seja porque passavam à condição de disciplinas extracurriculares. Por sua vez, esse descaso pode ter sido reflexo da “opção” por um tipo específico de desprovincialização, por meio de um processo de internacionalização que valorizava apenas uma língua e cultura estrangeira, ou seja:

O estreitamento das relações de dependência econômica e tecnológica com os Estados Unidos fazia arrefecer as paixões pela França como ideal de modernidade e civilização. A tentativa de passar a fazer parte do mundo globalizado faz com que a opção seja também por um currículo mundial, que na época seguia o modelo norte-americano. Esta opção, na verdade, resulta na negação do ideal de desprovincialização, pois propicia o atrelamento a um único referencial cultural. (PICANÇO, 2003, p. 53).

Muito embora houvesse a proposta de rever os interesses do Estado, no que diz respeito ao incentivo da internacionalização por meio da negação da condição de província, podemos dizer que a implantação da LEI 5.692/71 contribuiu para o isolamento do Brasil dentro da América Latina, no sentido de que afastou a possibilidade de ampliação de oferta de maior diversidade entre as línguas estrangeiras na escola. A LEI 5.692/71 dava margem para
${ }^{5}$ Reproduzimos a forma adotada pela autora, Picanço (2003), para se referir à professora. 
que cada instituição a interpretasse a sua maneira - e dentro das suas possibilidades. Acompanhemos o que dizia a lei, no artigo $8^{\circ}$ :

Art. $8^{\circ} \mathrm{A}$ ordenação do currículo será feita por séries anuais de disciplinas ou áreas de estudo organizadas de forma a permitir, conforme o plano e as possibilidades do estabelecimento, a inclusão de opções que atendam às diferenças individuais dos alunos e, no ensino de $2^{\circ}$ grau, ensejem variedade de habilitações.

$\S 1^{\circ}$ Admitir-se-á a organização semestral no ensino de $1^{\circ}$ e $2^{\circ}$ graus e, no de $2^{\circ}$ grau, a matrícula por disciplina sob condições que assegurem o relacionamento, a ordenação e a sequência dos estudos.

$\S 2^{\circ}$ Em qualquer grau, poderão organizar-se classes que reúnam alunos de diferentes séries e de equivalentes níveis de adiantamento, para o ensino de línguas estrangeiras e outras disciplinas, áreas de estudo e atividades em que tal solução se aconselhe. (BRASIL, 1971).

Nesse sentido, com a necessidade de política linguística plurilíngue e a oferta de uma maior diversidade na área das línguas estrangeiras modernas, os professores de línguas estrangeiras, organizados em associações, fomentaram a criação de novos cursos no CELEM, criado nos anos 80 e abalizados pela Secretaria de Estado de Educação, nos anos 90 (PICANÇO, 2003). Desse modo, além de favorecer aos alunos mais opções no que diz respeito às línguas estrangeiras que seriam ofertadas no CELEM, também os professores seriam beneficiados, pois teriam a oportunidade de atuar em suas áreas de conhecimento, já que, devido à diminuição de cadeiras para as línguas estrangeiras, muitos deles tiveram que passar a atuar em outras áreas de conhecimento.

Uma maior diversidade de línguas estrangeiras a serem ensinadas na escola - ia à contramão da tradição do ensino monolíngue do inglês, já que essa era a única ofertada na grade curricular - até em razão da volta da redemocratização do ensino, despontam na América Latina novas possibilidades de ampliação da área do ensino das línguas estrangeiras.

Se, no início dos anos 80, a hegemonia do inglês era um fato dado e não contestado, a partir do processo de democratização do país ela passou a ser questionada cada vez mais. Com o trabalho das associações, entidades afins, e com a ajuda de consulados e embaixadas, foi possível a quebra do monolinguismo no ensino de línguas. (PICANÇO, 2003, p. 68).

Ainda que, conforme trouxemos anteriormente, a possibilidade de entrada de outras línguas estrangeiras nos currículos escolares estivesse vinculada a manobras políticas e econômicas como, por exemplo, investimentos de outros países na economia nacional brasileira, parece ter-se iniciado outra etapa, pautada por leis e diretrizes de bases educacionais a serem inseridas na reforma educacional brasileira a partir de 1996. Entretanto, se para ampliar 
a diversidade linguístico-cultural fosse preciso fazer acordos mercantis, na década de 90, o MERCOSUL confirma que a política linguística não se estabelece separadamente da política econômica e social.

Por causa da criação do Mercosul, na última década o espanhol começa a dividir esse cenário, mais por motivos econômicos do que por uma intenção integradora do ponto de vista social e cultural. [...] a partir do início dos anos 90, o idioma começou a ser oferecido em várias escolas particulares e públicas como disciplina escolar, obrigatória ou opcional. (PICANÇO, 2003, p. 69).

Ao longo de sua trajetória, o ensino e a aprendizagem das línguas estrangeiras parecem ter se deparado com tantos problemas que a realidade do seu ensino formal na escola começou a tomar outros rumos somente a partir da década de 90 . Ora incluída no tronco comum, ora passando à parte diversificada do currículo, o tratamento dado a essa disciplina deixou a desejar em vários sentidos. Um dos problemas que podemos indicar diz respeito ao tratamento que a disciplina recebeu e recebe na formatação da grade curricular escolar. É possível que tal movimento vivenciado pelas línguas estrangeiras possa ter desencadeado determinadas crenças recorrentes a respeito do ensino e aprendizagem de línguas estrangeiras na escola.

Explicamos: a geração dos anos 80 (e aqui nos incluímos) foi educada formalmente em uma escola que afirmava que a disciplina de língua estrangeira não reprovava; o professor que ministrava as aulas de língua estrangeira, em geral, o fazia para preencher sua carga horária. Ou seja, nem sempre o professor que lecionava inglês (ou outra LE) tinha formação na área. Assim, grosso modo, os professores faziam de conta que ensinavam e os alunos, que aprendiam (ZAGURY, 2006). Estudos indicam que esse formato utilizado para com as línguas estrangeiras na educação básica pode ter influenciado a geração que crê que não se aprende língua estrangeira na escola pública (LIMA, 2011). Vejamos o que dizem os PCNs/BRASIL (1998) sobre o ensino de língua estrangeira:

A primeira observação a ser feita é que o ensino de Língua Estrangeira não é visto como elemento importante na formação do aluno, como um direito que lhe deve ser assegurado. Ao contrário, frequentemente, essa disciplina não tem lugar privilegiado no currículo, sendo ministrada, em algumas regiões, em apenas uma ou duas séries do ensino fundamental. Em outras, tem o status de simples atividade, sem caráter de promoção ou reprovação. Em alguns estados, ainda, a Língua Estrangeira é colocada fora da grade curricular, em Centros de Línguas, fora do horário regular e fora da escola. Fora, portanto, do contexto da educação global do aluno (BRASIL, 1998, p. 24, grifos nossos).

Desse modo, é possível afirmar que o ensino das línguas estrangeiras na educação básica sofreu alguma mudança em razão da nova Lei de 
Diretrizes e Bases (1996). Para Zagury (2006), a implantação dessa lei propôs somente mudanças nas atitudes dos profissionais inseridos nos contextos educacionais, sem considerar, entretanto, a necessidade de propor soluções para a falta de capacitação dos professores por meio do investimento na formação continuada, por exemplo:

A despeito do que preconizou a lei de Diretrizes e Bases em 1996, ano de sua entrada em vigor, e que também marcou o início da década da chamada Década da Educação, persistem no Brasil professores leigos; muitos não recebem um salário mínimo mensalmente; outros leem e escrevem mal. Mas, apesar de tudo isso, as autoridades esperam que o professor, assim, de hora para a outra, aprenda assuntos que nunca foram sua escolha profissional; e também que, num passe de mágica, mude sua metodologia de ensino com entusiasmo e empenho [...] No Brasil, as mudanças educacionais têm sido 'de papel', ocorrem na 'lei. (ZAGURY, 2006, p. 44-45).

O desabafo da autora se refere à educação formal em sentido amplo, mas em relação à situação dos professores de línguas estrangeiras, a descrição se encaixa perfeitamente, uma vez que, em 1996, a Lei de Diretrizes e Bases da Educação Nacional nº 9.394 (LDB/96) orientava que a oferta da língua estrangeira era obrigatória no ensino fundamental. As escolas deveriam optar pela língua que ofertariam de acordo com suas possibilidades (Art. $26 \S 5^{\circ}$ ). No caso do ensino médio, a lei sustentava que fosse incluída uma língua estrangeira moderna, de caráter obrigatório e uma segunda língua eleita pela comunidade escolar como optativa, de acordo com a capacidade da escola (Art.36, Inciso III). Ou seja, mudanças foram propostas, entretanto a preocupação em definir a obrigatoriedade da oferta da língua espanhola abre novos precedentes para as escolas. Como definir que língua seria obrigatória? De acordo com os Parâmetros Curriculares Nacionais, alguns fatores precisam ser considerados, quais sejam:

O fato de que as condições na sala de aula da maioria das escolas brasileiras (carga horária reduzida, classes superlotadas, pouco domínio das habilidades orais por parte da maioria dos professores, material didático reduzido a giz e livro didático etc.) podem inviabilizar o ensino das quatro habilidades comunicativas. Assim, o foco na leitura pode ser justificado pela função social das línguas estrangeiras no país e também pelos objetivos realizáveis tendo em vista as condições existentes. (BRASIL, 1998, p. 21).

Segundo Almeida Filho (2009), a “valorização” do ensino de leitura em detrimento do trabalho com as quatro habilidades tem base na história, diga-se de passagem, pouca relevância das disciplinas de línguas estrangeiras dentro do currículo, que, por sua vez, valorizava o ensino da língua materna:

O descomprometimento oficial com o ensino escolar das línguas confirmado e reconfirmado pelas autoridades escolares no desdém que se dedica à 
disciplina deu ainda um passo decisivo nos anos 90 com a prática generalizada da terceirização do ensino de línguas mediante contrato com escola de línguas das cidades. O propósito educacional já debilmente previsto e praticado da aprendizagem de línguas sofreu com isso outro duro revés. (ALMEIDA FILHO, 2009, p. 39).

Por outro lado, é importante não perder de vista que, apesar de estarmos no século XXI, isso não significa que o currículo escolar em vigência atualmente seja tão diferente daquele proposto, em 1917, cujo objetivo era capacitar o indivíduo para tecnicamente desenvolver alguma função, como os trabalhos em linha de montagem, como bem lembra Tadeu da Silva (2004).

Por isso, podemos afirmar que a inclusão ou a exclusão de uma disciplina de língua estrangeira nos currículos é um processo que se vincula a uma visão de política linguística veiculada em documentos oficiais, cujos princípios nem sempre vão ao encontro das possibilidades de ensino e aprendizagem plurilíngue para a aquisição de conhecimento de forma mais ampla. Para Almeida Filho (2009, p. 66), ensinar "uma língua estrangeira equivale a [ensinar] outra língua em outra cultura de um outro país pela qual se desenvolve um interesse institucionalizado em conhecê-la”.

O trajeto da inclusão/exclusão das línguas estrangeiras nas grades curriculares no Brasil está relacionado a determinados fatos políticos, econômicos e sociais, os quais foram decisivos para a manutenção ou não do ensino de determinada língua estrangeira na grade curricular das escolas de educação básica. Vejamos:

Constatamos, em primeiro lugar, que as finalidades de ensino da língua estrangeira, no geral, e do espanhol, especificamente, respondem tanto a expectativas políticas do governo, como a expectativas culturais da sociedade, em seus vários segmentos, representados, muitas vezes, por interesses antagônicos. (PICANÇO, 2003, p. 186).

Nesse sentido, podemos dizer que a trajetória aqui apresentada sucintamente permite que nos situemos a respeito de como se deram os diversos processos de inclusão e exclusão das disciplinas de línguas estrangeiras nos currículos escolares brasileiros, do século XIX ao início do século XXI. A partir de então, mais especificamente em 2005, depois do advento do MERCOSUL (em 1991), a partir do decreto da a LEI 11.161/2005 que trazia a obrigatoriedade da presença da disciplina de língua espanhola nas escolas públicas de ensino médio. Pela lei, a oferta é obrigatória, mas a matrícula do aluno, facultativa e as escolas disporiam de cinco anos, a partir da data da publicação da lei, para se adaptarem a ela.

Por outro lado, a inserção da língua espanhola no currículo, como disciplina de oferta obrigatória, conforme a LEI 11.161/2005, não parece desvelar que os estudos deste idioma tenham se fortalecido durante o período de 2005 até 2017, ano da revogação lei.
${ }^{6}$ Conforme afirmado anteriormente, a lei 11.161/2005 provavelmente esteja no cerne dos acordos comerciais, especialmente do MERCOSUL, mas não somente com os países da América Latina já que a Espanha, depois de sua implantação, passou a investir fortemente na formação de professores de espanhol aqui no Brasil (FERNÁNDEZ, 2005). 
Desde 2009, o Ministério da Educação (MEC) esclarece, em sua página na Internet, qual a situação da língua espanhola no Brasil. Ainda naquele ano, o então ministro Fernando Haddad trouxe a público, por meio de uma carta de intenções ${ }^{7}$ firmada entre o Instituto Cervantes e o governo federal, a notícia de que a língua espanhola passaria a ser levada às escolas pela educação a distância com a instalação de banda larga, nas escolas do país.

A informação chocou os professores de língua espanhola do Brasil, pois estes estavam confiantes na possibilidade de que seriam ofertadas novas cadeiras, nas escolas, para a área. Mas, ao contrário do que esperavam, o Instituto Cervantes, órgão diretamente ligado ao governo espanhol, seria o único responsável pela capacitação e formação dos futuros responsáveis pelo ensino do Espanhol/Língua Estrangeira nas escolas brasileiras.

Por essa razão, perguntamos: houve verdadeiramente alguma mudança significativa na condução destas disciplinas? Elas passaram a ser tratadas como importantes para a formação do aprendiz brasileiro? Para refletir sobre tais questionamentos, nos apoiamos nos Parâmetros Curriculares Nacionais (1998), que apresentam alguns dos propósitos que justificam a presença das línguas estrangeiras nas grades curriculares, a saber:

- estender o horizonte de comunicação do aprendiz para além de sua comunidade linguística restrita própria, ou seja, fazer com que ele entenda que há uma heterogeneidade no uso de qualquer linguagem, heterogeneidade esta contextual, social, cultural e histórica. Com isso, é importante fazer com que o aluno entenda que, em determinados contextos (formais, informais, oficiais, religiosos, orais, escritos, etc.), em determinados momentos históricos (no passado longínquo, poucos anos atrás, no presente), em outras comunidades (em seu próprio bairro, em sua própria cidade, em seu país, como em outros países), pessoas pertencentes a grupos diferentes em contextos diferentes comunicam-se de formas variadas e diferentes;

- fazer com que o aprendiz entenda, com isso, que há diversas maneiras de organizar, categorizar e expressar a experiência humana e de realizar interações sociais por meio da linguagem. (Vale lembrar aqui que essas diferenças de linguagem não são individuais nem aleatórias, e sim sociais e contextualmente determinadas; que não são fixas e estáveis, e podem mudar com o passar do tempo.);

- aguçar, assim, o nível de sensibilidade linguística do aprendiz quanto às características das Línguas Estrangeiras em relação à sua língua materna e em relação aos usos variados de uma língua na comunicação cotidiana;

- desenvolver, com isso, a confiança do aprendiz, por meio de experiências bem-sucedidas no uso de uma língua estrangeira, enfrentar os desafios cotidianos e sociais de viver, adaptando-se, conforme necessário, a usos diversos da linguagem em ambientes diversos (sejam esses em sua própria comunidade, cidade, estado, país ou fora desses). BRASIL (1998, p. 92).

\footnotetext{
${ }^{7}$ Mais informações em: http://portal. mec.gov.br/index. php?option=com_ content\&view $=$ article\&id=14072
} 
A proposta parece relevante e bem justificada, já que o próprio documento defende a presença de um plurilinguismo nas grades curriculares. Entretanto, a política praticada verdadeiramente para com as línguas estrangeiras, especificamente neste país, não afirma (ou afirma e depois se contradiz) se estas são ou não relevantes para a formação dos alunos.

Não é preciso ser pesquisador na área de educação para saber que aprender outras línguas auxilia na formação do cidadão, pois, quanto mais conhecemos sobre o outro mais nos inseriremos na diversidade. Quanto mais pudermos circular entre as diversas línguas, culturas, crenças e costumes, melhor estaremos preparados para atuarmos na sociedade. Conforme o documento PCNs/BRASIL (1998), o aprendizado das línguas estrangeiras nos possibilita enfrentar as mais diversas situações sociais e diárias, tanto em nosso bairro, cidade, país, quanto em outros lugares, com mais confiança. Circular entre as línguas é ter autonomia para compreender que língua é língua enquanto representação da linguagem de um grupo de pessoas ${ }^{8}$, tenha esta o status de línguas materna ou estrangeira.

Infelizmente, o que temos acompanhado é a promulgação de leis e documentos que intervêm diretamente no setor educacional, mas não garantem aplicabilidade e tampouco qualidade. De acordo com o que acompanhamos, nesse breve esboço sobre a história das línguas estrangeiras no país, os decretos e as leis - ou seja, toda forma de intervenção feita na educação parece não seguirem os preceitos de um plurilinguismo. Exemplo disso foi a última reforma do ensino médio na educação brasileira, com a promulgação da LEI 13.415/17, sancionada pelo presidente em exercício da República, Michel Temer, que reformula esta etapa da educação no País. O texto aprovado é o mesmo que foi confirmado pelo Senado e a Câmara dos Deputados. Teoricamente, o novo ensino médio prioriza a flexibilização da grade curricular, a articulação com a educação profissional e a educação integral com apoio financeiro do governo federal e novamente torna obrigatório o ensino da língua inglesa e optativo o ensino da língua espanhola ${ }^{9}$. Para estabelecer o inglês como única língua estrangeira na matriz curricular, a LEI 13.415/2017, inclusive, revoga a LEI 11.161/2005.

Assim, o que vemos no Brasil são professores de espanhol e de inglês principalmente, que procuram compreender por que o ensino das línguas estrangeiras nas escolas regulares fracassa (LIMA, 2011), enquanto os responsáveis pela elaboração das leis fixam e ditam normas, fazem alianças de interesses políticos e econômicos em que simplesmente promovem uma política linguística baseada no “toma lá dá cá”, usando uma expressão bem simples da língua portuguesa. Ou seja, não se faz uma política linguística baseada na possibilidade de estudos da diversidade, e sim de acordo com as vantagens políticas e econômicas que o país terá com esta ou aquela aliança para inserir ou excluir uma língua estrangeira dos currículos educacionais brasileiros.
${ }^{8}$ Barros (2005, p. 151) diz que "a língua e a linguagem têm uma relação de ir e vir com a sociedade. Elas são elementos sem os quais o homem não se organiza em sociedade. Quer dizer, a organização social depende da linguagem e os fatos da língua dependem dessa organização social e vão variando, mudando, construindo discursos, trabalhando com questões de ideologia e com todos esses elementos que estão ligados ao fato de que o homem é um ser linguístico e social, e de que essas duas coisas não se separam".

${ }^{9}$ Conforme o parágrafo $\S 8^{\circ}$ Os currículos de ensino médio incluirão, obrigatoriamente, o estudo da língua inglesa e poderão ofertar outras línguas estrangeiras, em caráter optativo, preferencialmente o espanhol, de acordo com a disponibilidade de oferta, locais e horários definidos pelos sistemas de ensino. 
Além disso, o movimento econômico, social e histórico desvela um mundo competitivo em que o conhecimento de línguas, ao mesmo tempo em que é considerado fundamental, por outro lado está associado aos entraves enfrentados no passado. Estes, por sua vez, não parecem ter mudado muito, considerando que as autoridades continuam dando pouca importância à qualidade do ensino ofertado. Parece que sua preocupação cada vez mais se volta apenas à quantidade de pessoas que estão frequentando a escola (não que isso não seja fundamental - a escola deve ser para todos), e não propriamente à qualidade, que tem sido aferida por avaliações oficiais, como as do ENEM, PROVA BRASIL e PROVINHA BRASIL. Resta saber se os números revelados por essas avaliações indicam que estes alunos estão realmente aprendendo ou apenas refletem os números que satisfazem as instituições financiadoras internacionais.

Compreendemos que as políticas educacionais se responsabilizam por normatizar e fazer funcionar os mecanismos que regulam a educação e que o fazer político é um gesto que envolve pessoas, demanda vontade e interesses. Por isso, as práticas políticas abrangem fatores relacionados às aspirações dos sujeitos?

Neste sentido, entra em jogo um emaranhado de atributos de valores (como o de considerar que uma disciplina tem maior relevância que outra, por exemplo), em que as crenças pessoais e coletivas estão relacionadas, já que quando tratamos de compreender o lugar das línguas estrangeiras no currículo brasileiro não há como nos distanciarmos dos movimentos políticos, econômicos e sociais vivenciados pelo Estado brasileiro. Para quem são feitas as leis e em que direção seguem as políticas linguísticas?

\section{Considerações finais}

Ao concluirmos este artigo, consideramos que o currículo, enquanto documento, além de ser influenciado pela política, pela economia e pelos poderes instituídos percebe-se que os fatos aqui trazidos prenunciam movimentos desenvolvidos na sociedade como um todo que interferem diretamente na escola.

Por vezes e entendendo os professores e professoras de línguas que somos, precisamos perceber que mais significativo que trabalhar com o ensino e a aprendizagem de um sistema simbólico representativo da linguagem, quiçá seja trabalhar com as diversidades e aplicabilidades dos códigos linguísticos em interação, como forma de ampliar os nossos horizontes culturais e sociais enquanto seres humanos.

Por tudo isso, é que a língua, seja esta estrangeira, nativa, materna, segunda língua, língua de contato etc., o mais relevante para os agentes envolvidos no processo de ensiná-la ou aprendê-la é compreender que fazer política linguística é ter noção sobre o quanto esses processos envolvem o 
outro, por meio das ações do Estado sobre o currículo e sobre a sociedade como um todo. Segundo Hamel (1988), o movimento de política linguística envolve muitos interesses que podem gerar conflitos e resistências entre os grupos envolvidos que podem ser os majoritários (com força política e econômica) e os minoritários (em geral os grupos oprimidos).

Assim, os professores e as professoras de línguas estrangeiras, não podemos entender o percurso das línguas estrangeiras pelo currículo como algo trágico e nos reconfortarmos nos percalços do trajeto das línguas estrangeiras como algo dado, que nos leva ao conformismo. Se há uma política linguística em curso, a nossa responsabilidade é de cada vez mais pesquisarmos e levarmos essas discussões para as salas de aulas, para os projetos e para as nossas pesquisas, com o intuito de ampliarmos os debates e as perspectivas sobre os porquês do tratamento político para a inserção/ exclusão das línguas estrangeiras no currículo, pois, entendemos que praticar uma política linguística a partir do plurilinguismo pode ser uma forma de abarcar maior diversidade cultural e linguística por meio do currículo educacional praticado em sala de aula.

\section{Referências}

ALMEIDA FILHO, José Carlos Paes de. Linguística Aplicada: ensino de línguas e comunicação. 3. ed.. Campinas: Pontes e Arte Língua, 2009.

BRASIL. LEI n ${ }^{\circ}$ 9.394, de 20 de dezembro de 1996.Estabelece as diretrizes e bases da educação nacional. Disponível em: http://portal.mec.gov.br/ seed/arquivos/pdf/tvescola/leis/lein9394.pdf. Acesso 06 fev. 2012.

. Secretaria de Educação Fundamental. Parâmetros curriculares nacionais: terceiro e quarto ciclos do ensino fundamental: língua estrangeira / Secretaria de Educação Fundamental. Brasília: MEC/SEF, 1998.

. LEI 11.161, de agosto de 2005. Dispões sobre o ensino da língua espamhola. Disponível em: http://www.planalto.gov.br/ccivil_03/_ ato2004-2006/2005/lei/l11161.htm. Acesso em: 02 mar. 2015.

LEI 13.415 DE 16 DE FEVEREIRO DE 2017. Altera as Leis $\mathrm{n}^{\circ} \mathrm{s}$ 9.394, de 20 de dezembro de 1996, que estabelece as diretrizes e bases da educação nacional, e 11.494, de 20 de junho 2007, que regulamenta o Fundo de Manutenção e Desenvolvimento da Educação Básica e de Valorização dos Profissionais da Educação, a Consolidação das Leis do Trabalho - CLT, aprovada pelo Decreto-Lei $n^{\circ} 5.452$, de $1^{\circ}$ de maio de 1943, e o Decreto-Lei ${ }^{\circ}$ 236, de 28 de fevereiro de 1967; revoga a Lei $\mathrm{n}^{\circ}$ 11.161, de 5 de agosto de 2005; e institui a Política de Fomento à Implementação de Escolas de Ensino Médio em Tempo Integral. Acesso em 13 mar. 2017. 
CAPUTO, Ana Cláudia; MELO, Hildete Pereira de. A Industrialização Brasileira nos Anos de 1950: Uma Análise da Instrução 113 da SUMOC. Est. econ., São Paulo, v. 39, n. 3, p. 513-538, jul.-set. 2009.

HAMEL, Rainer Enrique. Direitos linguísticos como direitos humanos: debates e perspectivas. In.: OLIVEIRA, Gilvan Müller de. (Org.). Declaração Universal dos Direitos Linguísticos, novas perspectivas em política linguística. Campinas: Mercado de Letras, Associação de Leitura do Brasil (ALB). Florianópolis. IPOL, 2003.

. La política del lenguaje y el conflicto interétnico: problemas de investigación sociolingüística. In: ESCOLAR, Alberto et al. (Org.) Política Linguística na América Latina. Campinas: Pontes, 1988. p. 41-73.

LIMA, Diógenes Candido de. (Org.) Inglês em escolas públicas não funciona: uma questão, múltiplos olhares. São Paulo: Parábola , 2011.

LISBOA, Maria Fernanda Grosso. A obrigatoriedade do ensino de espanhol no Brasil: implicações e desdobramentos. Revista Sínteses, Campinas, v. 14, p. 199-217, 2009.

MACIEL, Lizete Shizue Bomura; NETO, Alexandre Shigunov. A educação brasileira no período pombalino: uma análise histórica das reformas pombalinas do ensino - Revista Educação e Pesquisa, São Paulo, v. 32, n. 3, p. 465-476, set./dez. 2006.

FERNÁNDEZ, Francisco Moreno. El Español en Brasil. In: SEDYCIAS, João. (Org.). O Ensino do espanhol no Brasil: passado, presente, futuro. São Paulo: Parábola , 2005. 18-24 p.

PESSOA DE BARROS, Diana Luz. In: XAVIER, Antônio Carlos; CORTEZ, Suzana. (Orgs.) Conversas com linguistas: virtudes e controvérsias da linguística. Rio de Janeiro: Parábola Editorial, 2005. p. 149-157.

OLIVEIRA, Gilvan Müller de. (Org.). Declaração Universal dos direitos linguísticos: novas perspectivas em política linguística. Campinas: Mercado de Letras, Associação de Leitura do Brasil (ALAB); Florianópolis: IPOL, 2003.

PICANÇO, Deise Cristina de Lima. História, memória e ensino de espanhol (1942-1990): as interfaces do ensino da língua espanhola como disciplina escolar a partir da memória de professores, métodos de ensino e livros didáticos no contexto das reformas educacionais. Curitiba: UFPR, 2003.

RIBEIRO DA SILVA, Elias. “[...] você vai ter que aprender inglês de qualquer jeito, querendo ou não!”: exames de línguas e política linguística 
para o inglês no Brasil. 2011, 194 f. Tese (Doutorado em Linguística Aplicada) - Universidade Estadual de Campinas, Campinas, 2011.

TADEU DA SILVA, Tomaz. Documentos de identidade: uma introdução às teorias do currículo. 2. ed. Belo Horizonte: Autêntica, 2004.

ZAGURY, Tânia. O professor refém: para pais e professores entenderem por que fracassa a educação no Brasil. Rio de Janeiro: Record, 2006.

Recebido em agosto/2018.

Aceito em janeiro/2019. 